\title{
Modeling the access modal split of passenger railway hub stations in the metropolis
}

\author{
J. Kou \& B. N. Gu \\ Key Laboratory of Road and Traffic Engineering of \\ the Ministry of Education, Tongji University, China
}

\begin{abstract}
Generally, the utility of traffic modes for passengers is taken into account in an inter-city link, but the utility of both ends is considered less. When taking a trip, passengers choose the access modes to the railway hub station first, so the utility of the access modes also has a significant effect on the whole trip. Precise access modal split of the railway station is profound for facility configuration of all the access modes and saving of the passengers' travel time. Based on a real traffic network, this paper aims at the utility of access modes, provides a framework of the access modal split of the passenger railway hub stations (PRHSs) in the metropolis, and analyzes the items and characteristics of utility of the access modes. It selects the access time, fare, types of luggage and per capita family income as the utility items. And through an RP survey at Shanghai railway station, it calculates the utility of the access modes and estimates the parameters. It concludes that the access time, fare and luggage types all have a negative effect on the access modes and the per capita family income has a positive effect on the taxi and K\&R access mode but a negative effect on the metro and bus access modes.
\end{abstract}

Keywords: metropolis, passenger railway hub station, utility function, access modal split.

\section{Introduction}

In intersections or terminal areas of a railway network, the railway hub constitutes a variety of railway lines, professional stations and other related equipment, serving transport deals with passenger, freight and grouping. The PRHS in China mainly serve the inter-city or transfer trips, that are barely within the city. A rail 
journey chain includes three parts: the access to the PRHS from the origination, the in-haul journey and the egress from another PRHS to the destination. Since the origination is often far from the railway stations, the utility of the access part plays an essential role in the whole journey. And people may change the use of rail because of the inconvenience of the access part.

In Chinese research, they focus on the modes choice of the inter-city link, and the access time at the end of the link is usually considered to be a certain value, which couldn't reflect the real utility of the whole railway trip chain in different zones in the metropolis [2,3]. Xin Wenhui [4] establishes the MNL model using two kinds of trip-based mode to forecast the access modal split of PRHSs within the city. The data sets that put in the modal include the personal attributes, family attributes, inter-city trip attributes and so on. However, it is difficult to gain these data sets in reality and the study do not verify the model with relevant data. Besides, the travel time and fare lack a specific calculation approach, which may cause an invalid utility. So how to get the utility and make it more realistic are the issues that need more attention.

The studies worldwide pay more attention to the access and egress modes choice of the rail journey, consisting of the behavior of commuter train users and other transport modes users [5-14]. They either use kinds of Logit model or use the regression model to analyze the factors that may affect the choice. In their studies, the data always stem from the revealed preference (RP) or stated preference survey (SP) or both surveys in the train, at the station or through telephone interviewing. Through the survey, the travel time, fare, the travellers' characteristics and the facilities of the station and other data can be obtained to put in the model. Since there is plenty of data for the model, their researches usually focus on the estimation of the parameters and the analysis of the factors based on the estimation results. However, when the survey is limited for some reasons, such as security or the policy issues, the data would be scanty and the model would not be supported because of the lack of data. Thus it should develop an approach to calculate the main factors in the model, such as access time, fare, and some personal attributes. A number of studies have attempted to analyze the different variables that affect the modal split, ranging from individual mode choice, which in turn depends on individual and mode characteristics, to land use and population density, even weather [13].

Given the previous work, it is obvious that the Chinese studies mainly focus on the improvement of utility items of the inter-city link, but ignore the influence of the ends. And the studies worldwide present various factors, at micro or macro level. However, the studies may not have a deep and specific investigation about the access time, fare and luggage types enough. Although the RP and SP surveys can get a lot of data, people may not remember the access time clearly, especially in the SP survey, people may estimate the time more incorrectly in the fictitious context. So if the main factors, like time and fare, can be calculated directly and precisely, which don't rely on the survey, it may lead to more precise access modal split and higher service of traffic network.

Focusing on the issues above, this paper provides an overall structure of calculation of access modal split of PRHS first, then analyzes the main factors 
of the utility and provides the specific approach to calculate the utility items, and meanwhile considering the types of luggage and per capital family income (PCFI) to improve the utility function. Through a simple survey at Shanghai railway station, it estimates the parameters of the multinomial logit model (MNL), i.e. the model of access modal split. Thus it may provide a base for the modal split ratio of modes between the cities.

This paper is organized as follows: Section 2 displays the framework of access modal split, which contains the utility function and MNL model in this paper. Section 3 gives the specification and calculation of the utility items. Section 4 describes the data used in the analysis and shows the results of the estimation and test which are discussed. Section 5 ends the paper with conclusion and further discussion.

\section{The framework of access modal splitting}

There are more than one PRHS in the metropolis, a question may come up that when passengers take a trip, they will choose the access modes or the station first. Some studies have investigated the relevant issues $[12,15]$. Givino and Rietveld [12] think that passengers choose the access modes before the station. Because there are eleven stations in Amsterdam that people can choose several stations simultaneously and can easily get to the stations through simple structure of access modes. So they usually choose the station first. Chakour and Eluru [15] make comparisons about two sequences, and it concludes that the young prefer to choose the station first. However, on account of the function orientation of railway transport and the habits of passengers in China, passengers always choose the station first, then choose the access modes. At present, the regular methods of access modal split include regression [8, 14-16] and kinds of Logit models [7, 9, 10, 12-13, 17-19]. Among the studies, they care about the comprehensive and possible factors that affect the travelers' behavior. Nevertheless, the real and valid utility value and how to get it are still unknown.

The MNL has the IIA characteristic, which needs to be modified, such as using NL. However, with multi-access modes, many alternatives and lots of survey objects, it will be troublesome and take lots of time to cope with the data. On the premise of little difference between the results and the inconvenience of surveying, using MNL can estimate the parameters with fewer data. Santos et al. [13] summarise and analyze the research about factors that affect modal split. The factors include the city size, ownership of cars, income, age, households with children, fare of public transport, the frequency of public transport, rain, population density, travel distance, the mixed land use. Among these factors, the distance is positive to the motorized modes, and the fare is negative to the public transport. Through the comparison between estimate and test results of the MNL, NL and MXL, the difference between MNL and NL is little. Therefore, this paper will use the MNL to cope with data quickly and rely on less data.

In order to gain the split rate of access modes, it provides the overall framework first which explain the operating procedures, and after which the 
specific and essential parts will be analyzed. The detailed operating procedures are seen (fig. 1).

In the overall framework, the MNL mode and its function form is as follows [1]:

$$
\begin{gathered}
\boldsymbol{P}_{i n}=\frac{e^{\lambda V_{i n}}}{\sum_{j \in A_{n}} e^{\lambda V_{j n}}}=\frac{1}{\sum_{j \in A_{n}} e^{\lambda\left(V_{j n}-V_{i n}\right)}} \\
V_{i n}=\sum_{k}^{K} \beta_{k} x_{k i n}
\end{gathered}
$$

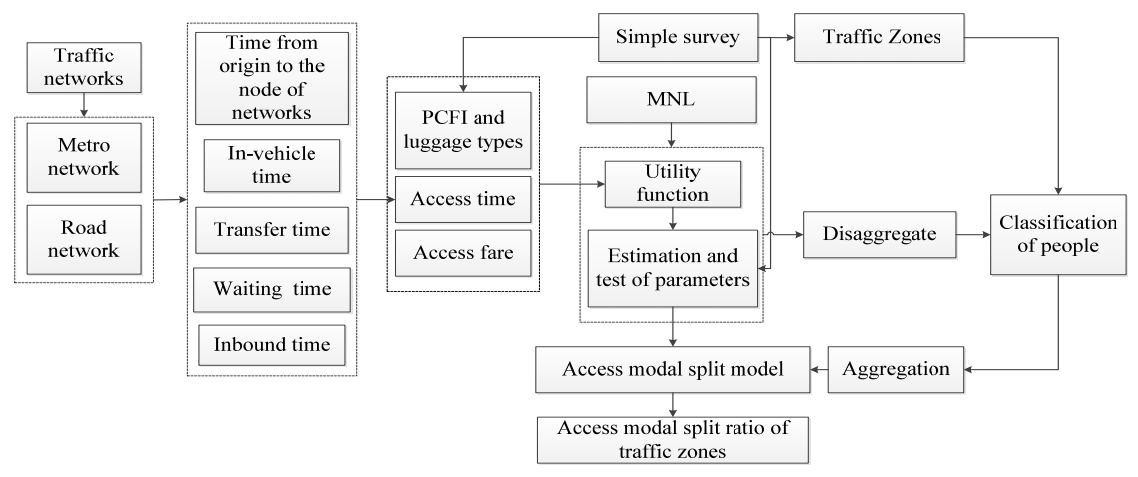

Figure 1: The framework of access modal split calculation approach.

\section{The specification and calculation of the utility items}

\subsection{Descriptive analysis}

Passengers get to the railway station through access modes. Intuitively, the factors that affect the choice of access modes include three parts: the characteristics of the access networks, the individual and stations. As with the characteristics of access networks, it refers to the networks of metro and road which provide different accessibility and service quality. In the macro views of the access networks, the access and egress time may be influenced by the change of population and landuse. Different access modes rely on different networks. For example, if you choose the metro, the metro and road networks may all be used. But if you choose the walk access mode, the road network may be used only. Thus, different access modes lead to different access time, which affects the access modal split. The accessibility of the traffic networks should be considered separately for the different levels due to its performance, like travel time, fare and comfort. The studies didn't consider the road and railway network simultaneously, which affect the relations between accessibility and population growth in Finland [20]. On the 
other hand, from a micro perspective, the waiting and transfer time at the access nodes will be affected.

Passengers have individual attributes and travel attributes. The PCFI level, carrying luggage or not, to a certain extent, will affect the access modes choice [18]. In general, car ownership is found to increase the share of trips by car and decrease the share of trips by public transport [21]. People with higher PCFI or carrying pieces of luggage may be in favor of the taxi with a comfortable environment, and the people with lower per capita family income will choose the general public transport in the absence of emergency. Carrying luggage will cause inconvenience to passengers, especially the large weight or large size. When using public transport with large luggage, passengers need to carry them upstairs and downstairs in a metro transfer station, and will perceives much more time than the real situation due to the physical and psychological factors, The change of the access modes utility may cause the change of the access mode choice and ratios.

Given the previous works, they have revealed some shortcomings. Focus is exclusively placed on total travel time as opposed to the specific access utility. So the access time and fare of different access modes, the PCFI level and the types of luggage are considered in this paper.

\subsection{The utility function}

The access time refers to the time from origination to the PRHS using different access modes. Specifically, it includes the time from origination to a certain node of the access modes, in-vehicle time, transfer and waiting time and the inbound time.

The cost of public transport and taxi refer to the fare. By comparison, the cost of personal car consists of car-purchasing fee and use-cost regardless of parking cost.

The PCFI is divided into 6 groups according to the tax levels of personal income tax and the dwellers' income distribution in China. Six groups are represented as 1 to 6 respectively.

3 kinds of the luggage types are considered into the utility function. The A type refers to no luggage or one handbag. B type means one light draw-bar box and 2 or 3 handbags. $C$ type means heavy draw-bar box or big woven bag. A, B, $\mathrm{C}$ are represented as 1, 2, 3 respectively.

As described above, the utility function is shown as follows:

$$
\begin{gathered}
V_{i, n}=\beta_{i 1} f_{i}+\beta_{i 2} \sum T_{i}+\beta_{i 3} \varepsilon_{\text {fincome }}+\beta_{i 4} \varepsilon_{\text {luggaage }} \\
i=\text { walk, metro, bus, taxi,private car }
\end{gathered}
$$

$f_{i}$ is the fare spent on access modes. $\sum \mathrm{T}_{\mathrm{i}}$ is the total access time of the $\mathrm{i}$ access mode. $\varepsilon_{\text {fincome }}$ and $\varepsilon_{\text {luggage }}$ are the items of individual characteristic as described above. $\beta_{i 1}, \beta_{i 2}, \beta_{i 3}, \beta_{i 4}$, are the parameters of the utility items. 


\subsection{The specification of the access time}

The railway network within the metropolis in China is still incomplete, so railway access mode is eliminated. Besides, as in the context of the metropolis, with a long access distance, people would almost take the motorized way to the station rather than the slow traffic, except that some people who living around the station would walk to the station. Therefore, this paper take the walk, metro, bus, taxi and private cars as the five access modes.

Based on the analysis above, we can gain the specification of the time item of five access modes, as following:

$$
\begin{gathered}
\sum T_{\text {metro }}=\left(\sum_{j} \frac{L_{j}}{v_{j}}+t_{w}\right)+\left[\sum \frac{L_{m}}{v_{m}}+\sum\left(\xi \frac{L_{t p}}{v_{t p}}+t_{w t r}\right)\right]+t_{\text {mib }} \\
\sum T_{\text {bus }}=\sum_{j} \frac{L_{j}}{v_{j}}+\sum\left(\frac{L_{b u s}}{v_{\text {bus }}}+t_{w b u s}\right)+t_{\text {bib }} \\
\sum T_{\text {taxi }}=t_{\text {walk }}+\frac{L_{t}}{v_{t}}\left[1+\alpha\left(\frac{V_{t}}{C}\right)^{\beta}\right]+t_{\text {wtaxi }}+t_{t i b} \\
\sum T_{\text {pcar }}=\frac{L_{p c}}{v_{p c}}\left[1+\alpha\left(\frac{V_{p c}}{C}\right)^{\beta}\right]+t_{w p c a r}+t_{p i b} \\
\sum T_{w a l k}=\frac{L_{w}}{v_{w}}+t_{w i b} \\
\xi=\frac{t_{0}}{t_{1}}
\end{gathered}
$$

$\xi$ is the ratio of $t_{0}$ to $t_{1} ; t_{0}$ is the perceptive walking time in transfer; $t_{1}$ is the actual walking time in transfer; $L_{j}, v_{j}$ refer to the in-vehicle length or speed respectively which access to the bus stop or metro station; $t_{w}$ refers to the waiting time of access modes to the metro station; $L_{m}, v_{m}$ refer to the metro length or speed respectively; $L_{b u s}, v_{b u s}, L_{t}, v_{t}, L_{p c}, v_{p c}$ refer to the in-vehicle length or speed of three kinds of access modes respectively; $L_{t p}, v_{t p}$ refer to the length or walking speed in the transfer passageway; $L_{w}, v_{w}$ refers to the walking length and speed from the origination to the railway station; $t_{w t r}$ $t_{w b u s}, t_{w t a x i}, t_{w p c a r}$ refers to the waiting time for the metro in transfer or bus stop, or for the taxi and private car respectively; $t_{m i b}, t_{b i b}, t_{t i b}, t_{\text {pib }}, t_{w i b}$ refers to the inbound time from nearest metro station, bus stop, parking lot to the station hall respectively. $V_{t}, V_{p c}$ refers to the volume of road. $C$ refers to the capacity of road. $\alpha, \beta$ are parameters.

\section{Data and estimation}

According to the Shanghai Statistical Yearbook 2014 [22], the area of Shanghai is $6340 \mathrm{~km}^{2}$, the permanent population at the end of the year is 24 million. Shanghai has more than 15 railway stations, 11 of them for passengers. However, only 3 of the passenger railway stations, however, undertake the major passenger missions. The average passenger delivery volume in a day are more than 100 thousand, even 
300 thousand in the holidays. However, the small railway stations like North Anting Railway Station, may only have less than 400 per day. In 2013, the railway operating mileage is $456 \mathrm{~km}$, the year passenger turnover is 7.5 billion man-km, and the year railway passenger delivery volume is 79 million, accounting for the total amount of passenger traffic (railway, highway, port and civil aviation) $50.03 \%$. Except the railway, at the end of 2013, Shanghai has opened 14 metro lines, a total of $548 \mathrm{~km}, 1338$ bus lines, $23,824 \mathrm{~km}$, to serve the trips within the city. The traffic networks are seen in Fig. 2.

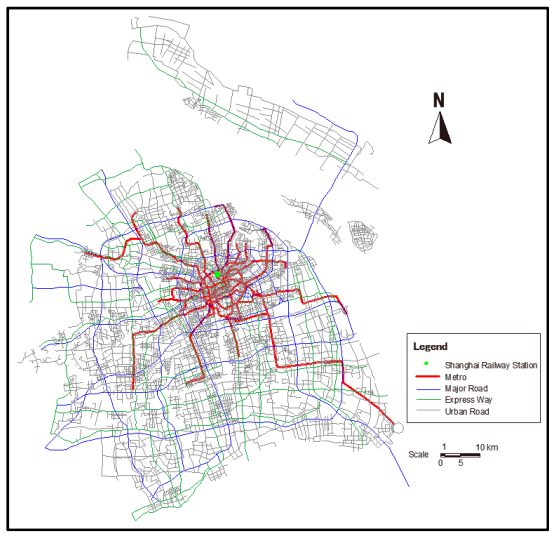

Figure 2: The traffic networks in Shanghai.

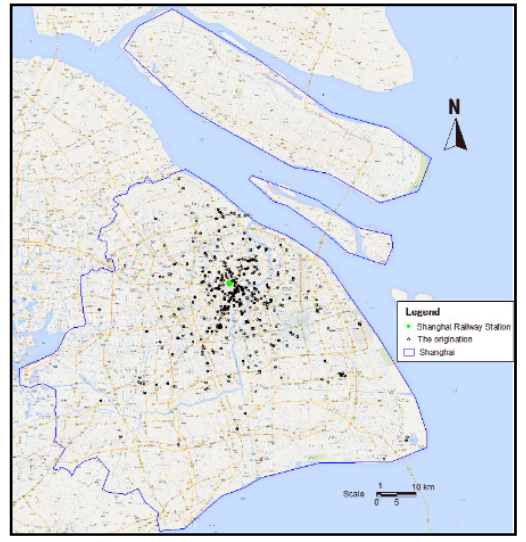

Figure 3: The originations of surveyed passengers in Shanghai.

The data in this paper comes from the field survey in the waiting hall of Shanghai Railway Station. There are 480 passengers interviewed in 12 waiting hall. Among these questionnaires, 397 of them are valid, for some passengers don't want to share the personal information. And 386 of the valid questionnaires are about the trips from regions in Shanghai to the other cities. The questionnaire contains the information of passengers' arrival and departure and individual attributes. With these information, the origination, the access modes, the perceptive walking time at the transfer, the check-in to the waiting hall time, age, sex, luggage types and per capital family income will be known, and the originations of the passengers are seen in Fig. 3. It assumes that the bus and taxi are available in all regions of the metropolis. The collected data is shown in Table 1. The private car access mode is only the passengers, i.e. there are no drivers coming to the Shanghai railway station to park their cars in the parking lot. The reason may be the lacking of parking facility provided by the station. It also may be the concept of the drivers that if they take a long trip by train, they prefer to leave the car in the residence community for some security reasons or they will just take the car for the trip. So the private car access becomes the kiss and ride access mode. 
62 Computers in Railways XV: Railway Engineering Design and Operation

Table 1: The main characteristics of the railway passengers surveyed $(\%$ of passengers made).

\begin{tabular}{|c|c|c|c|c|c|c|c|}
\hline Variables & Group & Group \% & Bus \% & Metro \% & K\&R \% & Taxi \% & Walk \% \\
\hline \multirow{4}{*}{ Sex } & Male & 68.4 & 8.3 & 64.8 & 4.2 & 22 & 0.8 \\
\cline { 2 - 8 } & Female & 31.6 & 14.8 & 56.6 & 4.9 & 23.8 & 0 \\
\hline \multirow{4}{*}{ Age } & Under 20 & 3.1 & 8.3 & 75 & 0 & 16.7 & 0 \\
\cline { 2 - 8 } & $21-30$ & 54.4 & 8.6 & 63.8 & 3.8 & 22.9 & 1 \\
\cline { 2 - 8 } & $31-40$ & 27.7 & 7.5 & 57.9 & 6.5 & 28 & 0 \\
\cline { 2 - 8 } & $41-60$ & 13.2 & 21.6 & 60.8 & 3.9 & 13.7 & 0 \\
\cline { 2 - 8 } & Over 60 & 1.6 & 33.3 & 66.7 & 0 & 0 & 0 \\
\cline { 2 - 8 } & Under 20 & 12.4 & 10.4 & 68.8 & 6.3 & 14.6 & 0 \\
\hline \multirow{4}{*}{$\begin{array}{c}\text { PCFI } \\
\text { thousand }\end{array}$} & $20-40$ & 20.2 & 10.3 & 70.5 & 0 & 19.2 & 0 \\
\cline { 2 - 8 } & $40-60$ & 23.3 & 12.2 & 75.6 & 3.3 & 7.8 & 1.1 \\
\cline { 2 - 8 } & $60-100$ & 20.2 & 14.1 & 55.1 & 9 & 20.5 & 1.3 \\
\cline { 2 - 8 } & $100-200$ & 15.8 & 6.6 & 52.5 & 4.9 & 36.1 & 0 \\
\cline { 2 - 8 } & Over 200 & 8 & 3.2 & 29 & 3.2 & 64.5 & 0 \\
\hline \multirow{3}{*}{$\begin{array}{c}\text { Luggage } \\
\text { types }\end{array}$} & 1 & 32.9 & 10.2 & 55.1 & 6.3 & 28.3 & 0 \\
\cline { 2 - 8 } & 2 & 51.6 & 10.6 & 69.3 & 2.5 & 16.6 & 1 \\
\cline { 2 - 8 } & 3 & 15.5 & 10 & 53.3 & 6.7 & 30 & 0 \\
\hline
\end{tabular}

Table 2: The main access cost characteristics of the railway passengers surveyed.

\begin{tabular}{|c|c|c|c|}
\hline & Max & Min & Mean \\
\hline Access time (min) & 330.9 & 4.1 & 59.5 \\
\hline Access fare (yuan/¥) & 160 & 0 & 12.2 \\
\hline Access distance (km) & 74.7 & 0.3 & 16.1 \\
\hline Waiting time in the hall (min) & 720 & 0 & 92.7 \\
\hline
\end{tabular}

Through the calculation of access distance, time and fare, and survey of the hall-waiting time, the data is sorted out in Table 2 and Fig. 4. Fig. 4 shows the access modal ratios in different groups of distance. It's obvious that the motorized modes are the main access modes to the railway station in comparison with walk. Besides, the public transport modes are the predominant access modes because the public transport are available conveniently except in the far-away suburban. The further away from the railway station, the more passengers would choose the metro access modes. But if the distance is so far away that it may take 
more than 2 hours to the railway station by bus or metro, passengers would rather choose the taxi mode though it is expensive. The walk access mode is only existed around the railway station. The average waiting time in the hall is more than one and half hours. It implies that the passengers usually get to the railway station in advance, though the departure time of the train is known ahead of time. This phenomenon is common in China and the access modes have a big difference with the access modal structures worldwide. It seems that more improved traffic networks is needed with more punctual schedules.

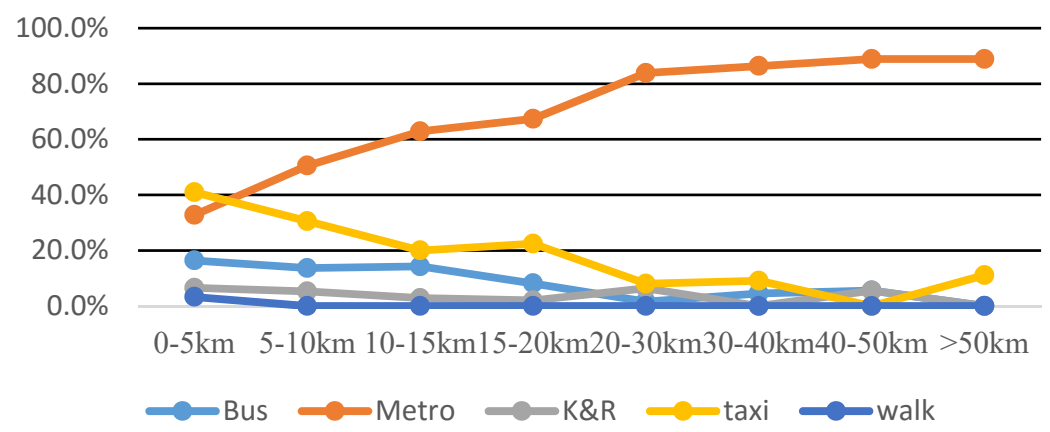

Figure 4: The proportion of five access modes in different groups of distance.

Using Matlab, it estimates and tests the parameters of the utility function stated in Section 3.2, and results are seen in Table 3. The access cost, such as time and fare, is negative to all access modes which means the higher the access cost is, the lower the probability of choosing a certain access mode will be. Besides, with more luggage, the utility of different access modes will be more negatively influenced.

In addition, it is shown that per capital family income is negative to both metro and bus, which indicates that one with higher per capital family income, he may not choose the public access modes. On the other hand, it is opposite to the taxi or K\&R access modes. This just accords with the observation in normal time.

Carrying light luggage, but having a high per capital family income, passengers would prefer to choose the taxi. The effect of luggage does not coincide with the analysis above. One explanation is that the one who has high per capital family income may not carry too much luggage because he could buy what he needs at stores in the journey. In comparison with Kiss and Ride, the per capital family income has more positive effect on the choice of taxi mode.

Furthermore, there is little difference between the influence that the luggage types and per capital family income have on the bus and metro mode. With more luggage and high per capital family income, passengers would give little preference to the public access modes. 
64 Computers in Railways XV: Railway Engineering Design and Operation

Table 3: Estimation results of all four alternatives.

\begin{tabular}{|c|c|c|c|c|c|c|}
\hline Alternative & Parameter & Coefficient & $\mathrm{T}$ test & $\begin{array}{l}\text { Hit rate of } \\
\text { alternative }\end{array}$ & $\begin{array}{l}\text { Overall } \\
\text { hit rate }\end{array}$ & $\begin{array}{l}\text { Maximum } \\
\text { likelihood } \\
\text { ratio }\end{array}$ \\
\hline \multirow{5}{*}{ Taxi } & Constant1 & 3.092 & 1.0347 & \multirow{5}{*}{0.8031} & \multirow{25}{*}{0.8622} & \multirow{25}{*}{0.4055} \\
\hline & Access time & -0.2634 & -1.3083 & & & \\
\hline & Access fare & -0.0069 & -1.5919 & & & \\
\hline & Luggage1 & -0.4562 & -0.4327 & & & \\
\hline & PCFI1 & 0.3059 & 0.6043 & & & \\
\hline \multirow{5}{*}{$\begin{array}{l}\text { Kiss and } \\
\text { Ride }\end{array}$} & Constant 2 & 2.5429 & 0.8214 & \multirow{5}{*}{0.956} & & \\
\hline & Access time & -0.2634 & -1.3083 & & & \\
\hline & Access fare & -0.0069 & -1.5919 & & & \\
\hline & Luggage2 & -0.5748 & -0.5209 & & & \\
\hline & PCFI2 & 0.0675 & 0.128 & & & \\
\hline \multirow{5}{*}{ Metro } & Constant 3 & 5.8306 & 1.9768 & \multirow{5}{*}{0.6554} & & \\
\hline & Access time & -0.2634 & -1.3083 & & & \\
\hline & Access fare & -0.0069 & -1.5919 & & & \\
\hline & Luggage3 & -0.4323 & -0.4135 & & & \\
\hline & PCFI3 & -0.1851 & -0.3691 & & & \\
\hline \multirow{5}{*}{ Bus } & Constant 4 & 4.2528 & 1.4218 & \multirow{5}{*}{0.8964} & & \\
\hline & Access time & -0.2634 & -1.3083 & & & \\
\hline & Access fare & -0.0069 & -1.5919 & & & \\
\hline & Luggage4 & -0.4738 & -0.4441 & & & \\
\hline & PCFI4 & -0.1858 & -0.3633 & & & \\
\hline \multirow{5}{*}{ Walk } & Constant & 1 & 1 & \multirow{5}{*}{1} & & \\
\hline & Access time & -0.2634 & -1.3083 & & & \\
\hline & Access fare & -0.0069 & -1.5919 & & & \\
\hline & Luggage & 1 & 1 & & & \\
\hline & PCFI & 1 & 1 & & & \\
\hline
\end{tabular}

\section{Conclusion and discussion}

This paper provides an overall framework of calculation of access modal split ratio of PRHS in metropolis, and analyzes the main factors in the utility function, In addition, it gets the specific form of utility function consisting of access time and fare, the per capital family income and the types of luggage. Furthermore, it displays the access modal structure of Shanghai railway station and analyzes the characteristics of its access modes. Moreover, it estimates and tests the parameters and concludes that the access cost is negative to the access modes choice, and it 
shows the negative effect of access time and fare and luggage types on the access modes and the positive effect of per capital family income on the Taxi and K\&R access mode but negative effect on the metro and bus access modes.

However, through the survey and estimation, it shows that the penalty of the luggage types do not have a decisive effect on the access modal split as we experienced. It needs more research on the expression of luggage types. Moreover, how to transform the factors like luggage types and the environment of metro transfer channel into monetary value is also required more research, because with the unified unit in the utility items, it can weigh the costs and benefits in terms of money, which might make the outcomes of the modal split more reasonable and effective.

With the development of the city, there will be more than one passenger railway hub station. And the passengers access to the railway station in a longer distance within the city. With the variety of the location, numbers, operation and organization of the hub railway stations, especially when the stations are connected to the each other, the railway access mode will save much more time in the long-distance trip when accessing to the target station. Thus the railway hub will not only fulfill the needs of the inter-city trips, but also the trips within the city, which could save more passengers' time and affect their access mode choice.

\section{References}

[1] Lu Huapu. Theory and Method in Transportation Planning (Second Edition) [M]. Beijing: TsingHua University Press, 2010.

[2] Li Qian. Research on Passenger Flow Forecasting Method of High-Speed Railway Based on Road Network [D]. Beijing: Beijing Jiaotong University, 2011.

[3] Zhang Min. Research on the Planning of Inter-city Rail Transit Network in South Sichuan Urban Agglomerations [D]. Chengdu: Southwest Jiaotong University, 2010.

[4] Xin Wenhui. Study on Urban Internal Traffic Demand Forecast Method of Railway Passenger Transport Hub [D]. Wuhan: Wuhan University of Technology, 2010.

[5] Wardman M. Inter-urban rail demand, elasticities and competition in Great Britain: Evidence from direct demand models [J]. Transportation Research Part E-Logistics and Transportation Review, 1997, 33(1): 15-28.

[6] Wardman M. Demand for rail travel and the effects of external factors [J]. Transportation Research Part E: Logistics and Transportation Review, 2006, 42(3): 129-148.

[7] Bhat C R, Sardesai R. The impact of stop-making and travel time reliability on commute mode choice [J]. Transportation Research Part B: Methodological, 2006, 40(9): 709-730.

[8] Brons M, Givoni M, Rietveld P. Access to railway stations and its potential in increasing rail use [J]. Transportation Research Part A: Policy and Practice, 2009, 43(2): 136-149.

[9] Bovy P, Hoogendoorn-Lanser S. Modelling route choice behaviour in multi-modal transport networks [J]. Transportation, 2005, 32(4): 341-368. 
[10] Molin E J E, Timmermans H J P. Context Dependent Stated Choice Experiments: The Case of Train Egress Mode Choice[J]. Journal of Choice Modelling, 2010, 3(3): 39-56.

[11] Givoni M, Rietveld P. The access journey to the railway station and its role in passengers' satisfaction with rail travel [J]. Transport Policy, 2007, 14(5): 357-365.

[12] Givoni M, Rietveld P. Do cities deserve more railway stations? The choice of a departure railway station in a multiple-station region [J]. Journal of Transport Geography, 2014, 36: 89-97.

[13] Santos G, Maoh H, Potoglou D, et al. Factors influencing modal split of commuting journeys in medium-size European cities [J]. Journal of Transport Geography, 2013, 30: 127-137.

[14] Shao C, Xia J C, Lin T G, et al. Logistic regression models for the nearest train station choice: A comparison of captive and non-captive stations [J]. Case Studies on Transport Policy, 2015, 3(4): 382-391.

[15] Chakour V, Eluru N. Analyzing commuter train user behavior: a decision framework for access mode and station choice [J]. Transportation, 2014, 41(1): 211-228.

[16] Krygsman S, Dijst M, Arentze T. Multimodal public transport: an analysis of travel time elements and the interconnectivity ratio [J]. Transport Policy, 2004, 11(3): 265-275.

[17] Debrezion G, Pels E, Rietveld P. Modelling the joint access mode and railway station choice [J]. Transportation Research Part E: Logistics and Transportation Review, 2009, 45(1): 270-283.

[18] Dissanayake D, Morikawa T. Investigating household vehicle ownership, mode choice and trip sharing decisions using a combined revealed preference/stated preference Nested Logit model: case study in Bangkok Metropolitan Region [J]. Journal of Transport Geography, 2010, 18(3): 402410.

[19] Liu C, Susilo Y O, Karlström A. The influence of weather characteristics variability on individual's travel mode choice in different seasons and regions in Sweden [J]. Transport Policy, 2015, 41: 147-158.

[20] Kotavaara O, Antikainen H, Rusanen J. Population change and accessibility by road and rail networks: GIS and statistical approach to Finland 19702007 [J]. Journal of Transport Geography, 2011, 19(4): 926-935.

[21] Pinjari, A., Pendyala, R., Bhat, C., Waddell, P.: Modeling residential sorting effects to understand the impact of the built environment on commute mode choice. Transportation 34(5), 557-573 (2007).

[22] ShangHai Statistical Yearbook 2014, http://www.stats-sh.gov.cn/tjnj/ tjnj2014.htm 